\title{
Gene marker database stirs up debate
}

[WASHINGTON] The US National Cancer Institute (NCI) is launching a project to identify, catalogue and enter into the public database its own set of single-nucleotide polymorphisms (SNPs, or 'snips') single-base variations in human DNA that are useful genetic markers.

The NCI's 'genetic annotation initiative', which comes hot on the heels of a similar project recently launched by the National Human Genome Research Institute (NHGRI), will seek out SNPs that mark 1,000 cancer-related genes, from tumoursuppressor genes to genes involved in metabolism and DNA repair.

The project, which also involves the National Center for Biotechnology Information, will receive $\$ 1.6$ million this year, and planners have already chosen 300 of the 1,000 genes to be studied.

But the sample set that the NCI is using to launch the project - DNA from 10 individuals in the collection of Paris's Centre d'Etude du Polymorphisme Humain $(\mathrm{CEPH})$ - has raised eyebrows at the NHGRI, which last year launched its own massive effort to identify and make public 100,000 or more SNPs.

The genome institute's samples will come from up to 500 ethnically diverse Americans, including those of Asian, Native American, African and European descent. The CEPH collection, by contrast, is dominated by Caucasian samples from more than 60 extended families originally collected by researchers at the University of Utah for genetic mapping studies. Most polymorphisms are thought not to be specific to ethnic groups.

Richard Klausner, the NCI director, described the project at a meeting of the NHGRI's advisory council last week. But NHGRI's director, Francis Collins, told him

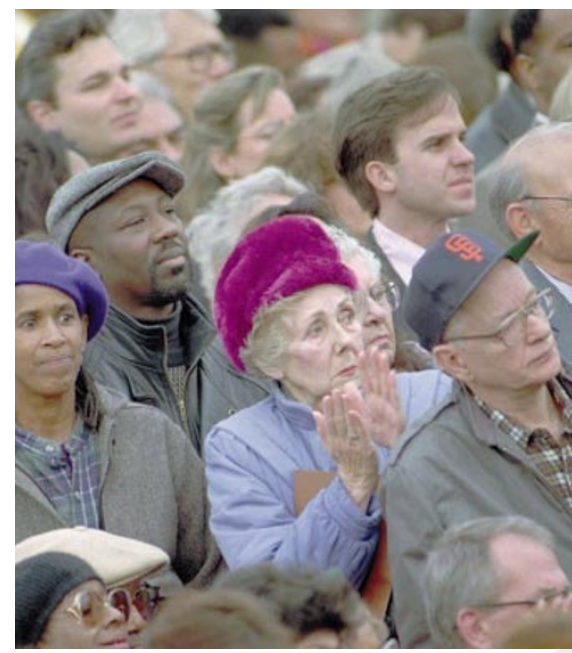

All sorts: critics claim the NCI's collection of SNPs will be too limited to Caucasian samples.

that he had "a little trouble with the notion that you're going to automatically overlook polymorphisms that are present in other ethnic groups than Europeans".

Collins said he feared that "going back later" to find SNPs in ethnically diverse groups will be "less attractive" to researchers than if SNPs were first identified in an ethnically mixed set of samples.

Collins also argued that, in creating a database using different samples from those being assembled by the NHGRI, the NCI would prevent a desirable situation in which "polymorphisms that are being discovered by groups all over the place will be attached to the same anonymous DNA samples".

Klausner responded that ethnically diverse groups can be examined in secondand third-generation studies once a relevant set of SNPs are identified. "I don't disagree with the importance of [studying diverse samples]," Klausner said. "It's just a question of whether it actually does need to be there as the up-front issue."

For Klausner, the project's most urgent goal is to identify SNPs, to make them accessible to researchers quickly, and to study which technologies are best at doing this - a question that remains unanswered.

Ken Buetow, who heads the human genetics programme at Fox Chase Cancer Center in Philadelphia, has been enlisted by Klausner to oversee the initiative with Michael Dean, chief of the human genetics section at the NCI's Laboratory of Genomic Diversity.

Buetow says that planners aim rapidly to study a second set of ethnically diverse samples, including some from the NHGRI's incipient database. But he says that initially there are compelling scientific reasons for using the CEPH collection. Because the collection includes large extended families, SNPs that are discovered can be rapidly validated through tracing their inheritance, ensuring that they are not laboratory artefacts.

The fact that the CEPH collection has already been extensively genotyped will allow investigators readily to fit identified SNPs into an existing map, as well as helping them to detect errors more easily.

But that does not satisfy everyone. "We would rather do all of these kinds of studies on a common set of DNAs," says Aravinda Chakravarti, a professor of genetics at Case Western Reserve University in Cleveland who heads an NHGRI working group that is planning that institute's SNP project. He adds that it would be "much more helpful" to look at "a diversity of types from multiple ethnic groups", such as those in the NHGRI sample group.

\section{Quebec urged to match supply and demand for science graduates}

[MONTREAL] An alliance of Quebec organizations called Science pour Tous (Science for All) is proposing that hightechnology companies should set aside 1 per cent of the public funds they receive to promote public understanding and appreciation of science.

The alliance was formed last November by seven organizations, alarmed at the growing shortage of trained scientific and technological personnel. A manifesto signed by 43 prominent educators, scientists and other public figures says that science and technology are not treated with due importance by Quebec institutions. It calls on scientists to share with the public "their questions, their discoveries, their sense of wonder, and even their distress".
A meeting of l'Association de la Recherche Industriel du Quebec heard that businesses are searching desperately for graduates in information technology, biotechnology and aeronautics. The province has recently produced fewer science graduates, but employment opportunities in these areas have increased by 91 per cent during the past 10 years, compared to 14 per cent in other sectors.

Despite this, the provincial education minister has reduced the number of hours devoted to the sciences in secondary schools and the federal government has announced the abolition next year of a programme called Science Culture Canada. This programme has provided up to $\mathrm{C} \$ 2.5$ million (US\$1.7 million) a year to non-profit groups that stimulate interest in science and technology among young people.

"With several hundred thousand dollars invested in Quebec, this programme has aided enormously in the promotion of science among young people," says Michel Gauquelin, vice-president of Science pour Tous and director general of the popular science magazine Quebec Science.

The programme was a victim of 1995 federal budget cuts, and is to hold its last competition for funds in April - despite the recommendation in a 1993 study by a consulting firm that it should be continued. The initial response to Science pour Tous from the Quebec government's ministry of culture and communication has been positive, says Gauquelin.
David Spurgeon 